\title{
Efficient Use of Water Resources in the Steel Industry
}

\author{
Valentina Colla ${ }^{1, *}$, Ismael Matino ${ }^{1}$, Teresa Annunziata Branca ${ }^{1}$, Barbara Fornai ${ }^{1}$, \\ Lea Romaniello $^{2}$ and Felice Rosito ${ }^{2}$ \\ 1 Scuola Superiore Sant'Anna, TeCIP Institute-ICT COISP, Via Alamanni 13B, 56010 Ghezzano, Italy; \\ i.matino@santannapisa.it (I.M.); t.branca@santannapisa.it (T.A.B.); b.fornai@santannapisa.it (B.F.) \\ 2 ILVA S.p.A. Taranto Works, Via Appia km 648, 74100 Taranto, Italy; lea.romaniello@gruppoilva.com (L.R.); \\ felice.rosito@gruppoilva.com (F.R.) \\ * Correspondence: v.colla@santannapisa.it; Tel.: +39-348-071-8937
}

Received: 29 September 2017; Accepted: 8 November 2017; Published: 10 November 2017

\begin{abstract}
In the steel sector water management aims at improving the sustainability of the production cycle, resulting in resource efficiency benefits and in reduced water demand and costs. To be reused, water needs to be cooled and desalinized to avoid salt concentration in water circulation systems. The presented work includes two case studies carried out in an integrated steelmaking plant, respectively, to evaluate the possible implementation of ultrafiltration and reverse osmosis to reduce salt concentration in water streams and to investigate, through modelling and simulation, a process integration solution to improve water efficiency. Results showed that most salts are removed by reverse osmosis and that its coupling with ultrafiltration allows obtaining very high quality water; reuse of desalinated wastewater resulted in being more suitable and economically viable than its discharge. Moreover, modelling and simulation showed that the considered blowdown could be reused without significant changes in the receiving water network area. The industrial implementation of water recovery solutions can lead to a decrease of fresh water consumption, effluent discharge, and to improvement of product quality and equipment service life. The considered desalination technologies are transferable and easily implementable, and modelling and simulation are very useful in order to evaluate process modifications before real implementation.
\end{abstract}

Keywords: desalination; modelling; process integration; reverse osmosis; simulation; ultrafiltration

\section{Introduction}

Ever more stringent environmental regulations have led the European process industries to carry out activities in order to achieve an efficient management and exploitation of resources [1]. Water is one of the most relevant and fundamental resources for most production cycles, therefore, the implementation of resource efficiency includes the reduction of freshwater intake and emission [2].

The steel industry uses large quantities of water. Nevertheless a very small amount is consumed, as most water is reused or returned to the source. Water is used not only in cooling operations, but also for other processes, such as descaling and dust scrubbing. All types of water are used in steelmaking processes. Fresh water is mainly used for processes and direct and indirect cooling, while seawater is normally used for once-through cooling after an antifouling pretreatment.

Steel is produced through two alternative routes: the integrated cycle, where steel is produced from virgin raw materials, and the electric route, which produces steel by melting scrap in an electric arc furnace (EAF). The average water intake for an integrated steelworks is $28.6 \mathrm{~m}^{3}$ per tonne of produced steel, with an average water discharge of $25.3 \mathrm{~m}^{3} /$ tonne of steel. For the electric route, the average intake is $28.1 \mathrm{~m}^{3}$ per tonne of steel, with an average discharge of $26.5 \mathrm{~m}^{3}$ per tonne of steel. Consequently, the overall water consumption per tonne of steel produced is low (from $3.3 \mathrm{~m}^{3}$ to $1.6 \mathrm{~m}^{3}$ ) and water losses are mainly due to evaporation [3]. To sum up, the overall water consumption 
in a steelmaking site is actually limited. Most of the consumed water is evaporated and around $90 \%$ (on average, $88 \%$ in an integrated plant and $94 \%$ in an EAF-based plant) of the water is discharged after cleaning and/or cooling and often used by other utilities [4].

As fresh water availability and quality represent major concerns, water resource management is an important challenge to face in order to improve sustainability of the production cycle. Water, as well as steel, can be reused and recycled. However, as the increase of water recycling, after cleaning and cooling, can decrease the water quality, steelworks are committed to reducing water use and consumption or to improve the cleaning technologies. Water needs to be cooled and desalinised, as the increase of salt concentration in water circulation systems (due to evaporation) can not only be an environmental issue, but also negatively affect plant equipment (e.g., in the rolling mills). For instance, phosphates can cause the eutrophication of the water environment, chlorides can lead to metal equipment corrosion, while carbonates lead to scale formation in the pipes, causing an increase of energy consumption.

Considering the desalination processes and the related crystallization of solid salt out of the brines (a by-product of the desalination process), significant amounts of energy are required with a consequent $\mathrm{CO}_{2}$ emissions increase. Statistical analyses of factors affecting specific energy consumption (SEC) have been exploited in order to predict the energy consumption of desalination. In addition, an economic analysis showed a weak statistical relationship between SEC and cost of water production [5]. Nevertheless, the quality of the recovered salts is usually of poor quality and, as a consequence, these salts cannot be re-used. Furthermore, they need to be disposed of in landfills, affecting the quality of the leachate.

In order to reach an efficient use of water resources in the steel sector, a holistic and balanced approach is needed, which considers actual consumptions without neglecting other aspects, such as water availability and quality, plant configuration, and energy efficiency [6]. Furthermore, as water-related challenges (i.e., availability, seasonal shortage, competition with other users) depend on regions and countries, it is important to have a local approach and a tailor-made regulatory framework. Both traditional and advanced wastewater treatments (e.g., chemical sedimentation/ clarification combined with flocculation) are focused on producing high-quality water, as well as highly efficient water recycling [2]. This has led to reduced extraction of groundwater [7]. Previous studies have been carried out in order to apply reverse osmosis (RO) and nanofiltration for the treatment and reuse of wastewater in other sectors, such as tannery [8] and textile industries [9]. In the steel sector, electrodialysis and ion exchange have been applied for the treatment of wastewater from rinsing of stainless steel etched in nitric acid and hydrofluoric acid [10]. In addition, the combination of ultrafiltration (UF) and RO has been tested for producing deionised water from surface waters [11]. A more efficient application of RO can be achieved through the combination with a pre-treatment, such as back-washable microfiltration (BMF) [12]. However, salts, microorganisms, and pollutants can cause membrane fouling in the RO process, reducing its efficiency. The application of pre-treatments (e.g., disinfection, acidification, addition of coagulants and/or flocculants, media filtration, and cartridge filtration) can prevent fouling. Moreover, as traditional pre-treatments are often not efficient in removing fine colloidal suspended solid organic matter, continuous microfiltration (CMF) and UF can be applied, resulting in high-quality water for industrial applications and cost reductions $[13,14]$.

In order to improve water recycling and reuse, preliminary investigations on process feasibility aim at identifying the most convenient solution. In this regard, process modelling and simulations (PM and S) represent valuable tools in the identification of different solutions to improve water efficiency and to analyse available process integration (PI) options for water systems, considering equipment and plant capabilities, efficiency and quality for process streams [15]. PI is defined by the International Energy Agency (IEA) as "systematic and general methods for designing integrated production systems, ranging from individual processes to total sites, with special emphasis on the efficient use of energy and reducing environmental effects" [16]. As far as the PI is concerned, over the 
last few years, some important results have been achieved in the energy [17] and water fields, through theoretical studies, pinch analyses [18], experimental campaigns and the use of PM and S [1,19-21]. In addition, in order to reduce water consumption and wastewater discharge, an optimization model and an evaluation index system for the water-use network of a steelwork has led to important results in water savings [22]. The implementation of PI-based solutions at the industrial level can limit the overall water consumption by reducing the water withdrawal [23-26]. Moreover, modelling has also been used to predict water quality of a river. This approach aimed to predict how changes in flow management and climate change can affect water quality [27]. In addition, referring to the assessment of investments for integrated water management, system dynamics modelling has supported the analysis of world water demand and supply trends by integrating also economic, environmental and social aspects [28].

As experimental tests are often difficulty to perform in real plants, PM and S can be applied to develop scenario analyses, through a virtual plant development. Simulation aims to assess solutions for improving resources management before their test and application at the plant level. It can be considered as a transversal tool which allows detailed analyses including all the relevant aspects which are relevant to assess the viability of the modifications of over-complex industrial processes $[29,30]$. Process simulation also allows evaluating unconventional scenarios or operating conditions that are difficult to assess and test [17]. Concerning the water management, simulations aim at assessing solutions to reduce freshwater intake before their real tests or applications, by evaluating the effects on the quality of the circuit and blowdown water (e.g., the salinity). For instance, simulations can be exploited to assess the application of UF and RO for reducing salt concentration in brackish water or wastewater to be reused in steelmaking processes. They can also support the assessment of the viability of blowdown reuse in some plant areas or the addition of a new treatment operation unit to reduce a particular contaminant (e.g., fluoride). Concerning water blowdown recovery, suitable characteristics of blowdown streams can allow their reuse as make-up water in other processes with or without pretreatments [31].

The work described in this paper concerns research activities carried out in an Italian iron and steel facility. The work objectives consisted in the investigation of the possibility to implement UF and RO in order to reduce salt concentration in water or to reuse wastewater in steelmaking processes as well as the possibility of blowdown reuse in some process areas. Standard techniques and advanced PM and $S$ tools have been coupled to assess the validity of process integration solutions or the considered desalination technologies before real implementation. On this subject, improvement of water reuse have been considered in an integrated way, taking into account technical constraints and saving potentials in terms of resources and costs.

In the integrated steelwork considered in this study, water is mainly used for plants cooling, for materials cooling and conditioning, as well as for process off-gas and by-product cooling and washing. On this subject, sea water and freshwater (from wells or from two rivers, Tara and Sinni, which are located close to the steelworks) are used. Sea water is subject to the antifouling treatment with $\mathrm{ClO}_{2}$ and, afterwards, used for indirect cooling and directly fed into the sewer. Wells and Tara waters have the same characteristics, namely high conductivity of about $3000 \mu \mathrm{S} / \mathrm{cm}$, due to the high salt content. On the contrary, water coming from Sinni River has a lower salt content and, consequently, lower conductivity (about $450 \mu \mathrm{S} / \mathrm{cm}$ ). The water network is equipped with a centralized RO treatment plant and three smaller RO plants for producing low salinity water of a dedicated plant. Each production plant is equipped with a water treatment line for cooling and removing pollutants, such as suspended solids and oils. These treatments include sedimentation and sand pressure filtration. In particular, sludge from continuous casting (CC) and from the hot strip mill (HSM) are subject to two sedimentation steps: the first one includes a pretreatment for larger particle removal, while the second step covers a deeper purification. The secondary sedimentation phase concerns coagulants and flocculants addition in clarifiers, with $\mathrm{pH}$ adjustment when required. This removal process can be 
optimized through carbon filters in order to further purify the waters that must be discharged into the sea, according to Italian legislation [32].

The described research works refer to two case studies. The first one concerns the water reuse and facility management in the water circuit of the HSM. The high chloride and carbonate concentration in the cooling water during the hot rolling can cause not only salt deposition on the strips' surfaces, affecting the quality of the strips, but also equipment corrosion and, consequently, reduction of the pipe service life. Salt elimination techniques have been analysed: in particular, the effectiveness of $\mathrm{RO}$ to remove salts has been investigated. The second case study concerns the investigation of water savings by coupling advanced PM and S tools to plant data analysis and standard evaluation techniques. These tools have been applied for evaluating the validity of PI solutions by considering the potential improvement of water reuse in an integrated way, taking into account technical constraints and quantifying savings, such as resources and costs. In particular, simulations of new treatments or direct reuses of liquid streams have been carried out.

A preliminary economic analysis has also been carried out in order to evaluate the viability of the industrial scale implementation of the desalination processes presented in this paper. To this aim, the payback period (PBP) has been computed. The PBP represents the time required to recover an investment by collecting savings and gains: the shorter the time for capital recovery, the more viable the investment. The PBP can be calculated as simple PBP (SPBP) or discounted PBP (DPBP). The SPBP is the ratio between the investment and the gross operating profit (the gross operating profit results before the taxes, but after the interest). The SPBP provides a preliminary evaluation of the level of risk related to an investment. However, it does not consider cash flows after the PBP of the project and it omits the time value of money [33,34]. On the other hand, the DPBP represents the period during the accumulated present value of the cash flows covering the initial investment outlay [35]. It provides a more accurate estimate of the time needed to recover an investment and here appears depending on the permeate and retentate stream prices. The achieved results coming from the preliminary economic evaluation showed significant advantages in implementing the selected solutions.

The paper is organized as follows: Section 2 provides the materials and methods exploited in the two considered case studies in the respective sub-sections; in Section 3 the experimental results are presented and discussed. Finally, in Section 4 some concluding remarks are provided.

\section{Materials and Methods}

\subsection{The First Case Study: Water Reuse in HSM}

At HSM water is used for cooling and for descaling. Physical-chemical treatments of the process water are usually scale sedimentation, oil decantation and chlorination with $\mathrm{NaClO}\left(12 \% \mathrm{Cl}_{2}\right)$. After hese treatments, the process water goes to the cooling tower and subsequently to the storage tank. A poor quality of water used for the cooling system of the HSM can negatively affect the hot rolled coils and some constraints need to be respected, as depicted in Table 1, where the desired characteristics of make-up water and recirculation water in HSM are shown. For this reason, the addition of make-up water with low salinity was needed.

Table 1. Desired features for make-up and recirculation water in HSM; in brackets not treated water values are shown.

\begin{tabular}{ccc}
\hline Parameter & Make-Up Water & Recirculation Water \\
\hline $\mathrm{pH}$ & $8(7-7.4)$ & $8.6(8-8.2)$ \\
$\mathrm{EC}(\mathrm{mS} / \mathrm{cm})$ & $0.2(3.2-3.4)$ & $1(4.8-5.1)$ \\
$\mathrm{Cl}^{-}(\mathrm{ppm})$ & $30(780)$ & $150(1170)$ \\
$\mathrm{HCO}_{3}{ }^{-}(\mathrm{ppm})$ & $95(400)$ & $475(430)$ \\
$\mathrm{Ca}^{2+}(\mathrm{ppm})$ & $25(170)$ & $125(200)$ \\
\hline
\end{tabular}


Water consumptions and discharges in the HSM for different supply options have been evaluated, compared to the current situation, where brackish surface water is used. During the assessment, the total evaporation loss was considered equal to $100 \mathrm{~m}^{3} / \mathrm{h}$ and a number of concentration cycles were considered that allows having the desired value of $\mathrm{Cl}^{-}$in the recirculation water.

After a deep analysis, two solutions among the considered options have been taken into account in order to improve the water management: the partial replacement of fresh make-up water with blowdown recovery after UF and RO processes, in order to minimize water needs and discharge flow rate, and the use of brackish groundwater after $\mathrm{RO}$ treatment, in order to control water consumption and to reduce discharges.

The second solution presented significant advantages. Although the groundwater contains high salt concentration, it is a supply water stream for $\mathrm{RO}$ with almost constant features. In addition, as it is free of bacteria and suspended solids, and characterized by a low value of the Silt Density Index (SDI), it requires only sand and filter cartridge filtration pretreatments. In particular, the UF is not required before RO, while it is necessary in the first solution. For this reason, in order to select one of the two mentioned solutions, the following aspects need to be considered: the legal limits for discharging chlorides and sulphates, when it is not possible to discharge into the sea (in the current Italian legislation there are no limits for chlorides and sulphates discharged into the sea) [32]; the water requirements and the availability from primary source; the costs of water from primary source.

A preliminary economic analysis highlights that the first solution provides significant cost savings. For this reason, the experimental activity was aimed at quantifying the water consumption from primary sources by blowdown reuse. In order to reach process constraints, desalination through RO of the cooling water in the recirculation system of HSM has been evaluated. The stability of the qualitative performance of RO has also been assessed. Until now, HSM receives make-up water, consisting of a mix of brackish water $(E C=3400 \mu \mathrm{S} / \mathrm{cm})$ and fresh water $(E C=200 \mu \mathrm{S} / \mathrm{cm})$. After the cooling of rolls and strips in the HSM, the recirculation water is treated through decantation, sand filtration, and cooled in the evaporative cooling towers. This fact leads to increase of salts concentration and, as a consequence, to relevant volumes of blowdown water. For this reason, in order to reduce salt concentrations from the cooling circuit as well as blowdown, tests have been carried out using a RO pilot plant (manufactured by Bernardinello Engineering S.P.A., Cadoneghe, Italy). As shown in Figure 1, the pilot plants includes: cartridge security filters in series with a filtration degree of $200 \mu \mathrm{m}$ and $50 \mu \mathrm{m}$ in series, UF unit under pressure, activated carbon filters, and two-stage RO units (two vessels for the first stage and one vessel for the second stage).

During four weeks ( $78 \mathrm{~h}$ operations) the volumes of treated water were $128.7 \mathrm{~m}^{3}$ of raw water, $123.2 \mathrm{~m}^{3}$ of ultrafiltrated water and $93.6 \mathrm{~m}^{3}$ of RO feed stream. Analyses of three samples (feed, permeate, and retentate) from the $\mathrm{RO}$ unit were carried out. In the first two weeks $\mathrm{RO}$ was fed with raw water and a part of retentate, leading to higher salinity both of the feed water and of the permeate.

Chemical treatments were performed before the filters. They consisted of continuous chlorination of raw water with a $12 \%$ solution of $\mathrm{NaClO}$, upstream of the security filters (providing a concentration of residual chlorine between $0.3 \mathrm{ppm}$ and $0.5 \mathrm{ppm}$ ) and continuous addition of antiscalant compound (containing phosphonates) in the RO feed water, to provide at least $1 \mathrm{ppm}$ of phosphonates.

In order to protect RO membranes (DOW BW 30-4040, The Dow Chemical Company, Midland, MI, USA) by removing colloids which are not previously eliminated through filtration, a UF (equipped with DOW SFP 2860 membrane, The Dow Chemical Company, Midland, MI, USA) stage for raw water was needed. Input and output samples were analysed in order to monitor the efficiency of the UF. However, the analysis of suspended solids, total iron, total silica, and reactive and colloidal silica did not explain the efficiency of this treatment, due to the high quality of the feed water. For this reason and due to the fact that the only parameter used for testing the UF efficiency was the SDI, which provides indications about the colloids content, the SDI was monitored. 


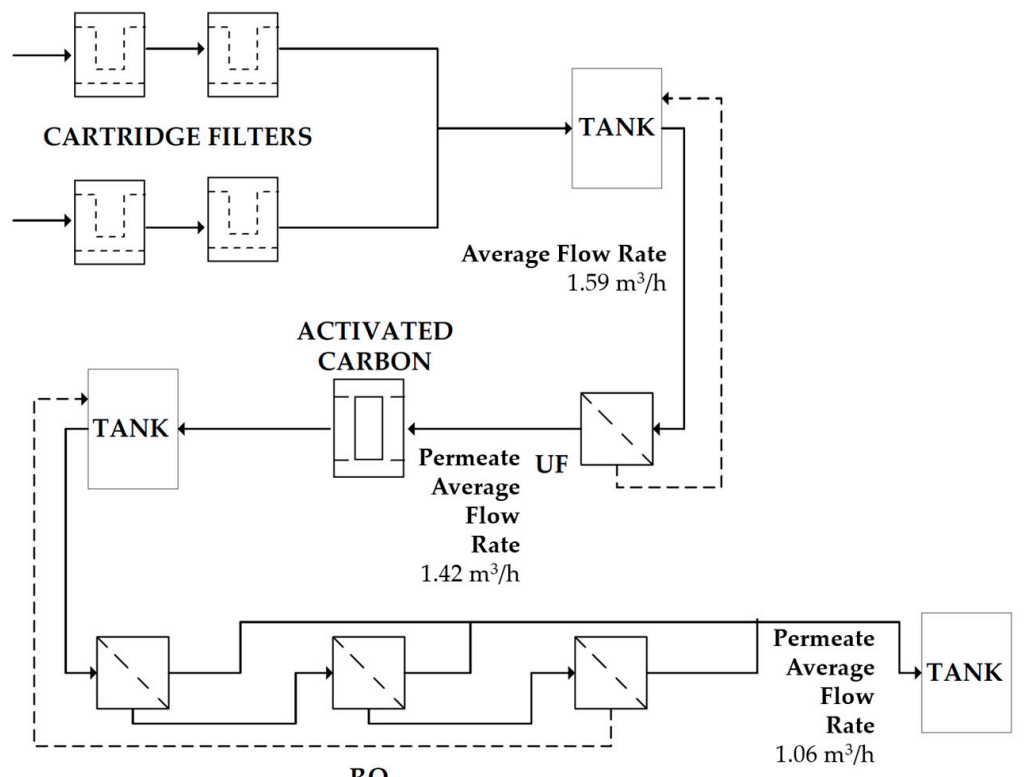

RO

\begin{tabular}{|l|l|l|l|}
\hline \multicolumn{3}{|l|}{ CONFIGURATION AND MAIN FEATURES OF DESALINATION PILOT PLANT } \\
\hline & & UF & RO \\
\hline Configuration & & Dead End Flow & Two Stages \\
\hline Membrane Type & & $\begin{array}{l}\text { 1 membrane } \\
\text { DOW SFP 2860 }\end{array}$ & $\begin{array}{l}\text { I stage: 4 membranes } \\
\text { II stage: 2 membranes } \\
\text { DOW BW 30-4040 }\end{array}$ \\
\hline Filtration Area & $\mathrm{m}^{2}$ & 51 & $\begin{array}{l}\text { I stage: } 28.8 \\
\text { II stage: 14.4 }\end{array}$ \\
\hline Max Flow Rate & $\mathrm{m}^{3} / \mathrm{h}$ & 6.1 & 3.6 \\
\hline
\end{tabular}

Figure 1. Flowchart diagram (with average experimental flow rates) and main features of desalination pilot plant.

\subsection{The Second Case Study: Investigation of Water Savings Through a Modelling and Simulation Approach}

A preliminary analysis pursued in the considered integrated steelwork has shown that the features of water blowdown streams of some plant areas comply with the constraints related to water used in other plant areas (directly or after pretreatments). Reuse and savings of water resources could, therefore, be possible. The evaluation of the real suitability of some identified solutions constitutes this second case study, by considering existing water treatment plants or adding new units (if required). The assessment was carried out through the exploitation of PM and $\mathrm{S}$ techniques in order to evaluate the effect of the reuse of the such blowdown streams before the real test or application.

The analysed solutions consist in the reuse of the blowdown of pipe coating plant $n^{\circ} 1$ (named PCP1) in pipe plant $n^{\circ} 1$ (named PP1) to replace partially the Sinni River freshwater and the reuse of coke-making area wastewater. The main features of these water streams are listed in the Table 2.

Table 2. Main measured parameters of analysed water streams.

\begin{tabular}{ccccc}
\hline Water Parameters & Unit & $\begin{array}{c}\text { Sinni River } \\
\text { Freshwater }\end{array}$ & $\begin{array}{c}\text { PCP1 Blowdown } \\
\text { Water }\end{array}$ & $\begin{array}{c}\text { Coke-Making Area } \\
\text { Wastewater }\end{array}$ \\
\hline $\mathrm{pH}$ & - & 8.1 & 7.0 & 7.3 \\
Electrical Conductivity & $\mu \mathrm{S} / \mathrm{cm}$ & 387 & 407 & 8562 \\
Suspended Solids & $\mathrm{mg} / \mathrm{kg}$ & 8.4 & $<5$ & - \\
Hardness & $\mathrm{mgCaCO} / \mathrm{L}$ & - & - & 35.7 \\
\hline
\end{tabular}


The use of holistic models is aimed at depicting in a simplified way common unit operations of resources usage to predict flow properties and plant area behaviour in common and uncommon scenarios. To this aim, simulation and optimization studies of industrial water networks have been performed.

Process model and simulation have been carried out through different tools, such as specialized commercial simulation software (i.e., Aspen Plus ${ }^{\circledR}$ ), ad hoc upgraded software (i.e., Water-Int), or MS Excel ${ }^{\circledR}$. This was due to the different details and complexity required, in order to assess the feasibility of a PI-based solution.

Excel-based mathematical models of some processes and treatments have been developed, by taking into account physical and process information, including mass balance equations for water and contaminants. Such models provide the main properties of output streams and are used to carry out preliminary investigations on the behaviour of unit operation. The developed models represent a water and processes library and they were implemented in the Water-Int tool.

Based on the Excel-model library, Water-Int software allows preliminary studies of simulation and optimization of the structure of an industrial water network. It provides suggestions of possible network modifications or arrangements that lead to economic and environmental improvements. For instance, all the feasible connections can be considered: water reuse, water regeneration and reuse, water regeneration recycling, local recycling around process and treatment units, as well as pre-treatment of feed-water streams.

In addition, in order to make complex simulations of water networks the specialized commercial simulation software Aspen Plus ${ }^{\circledR}$ has been used, by taking into account the water features that are usually monitored in a real plant. This software allows developing accurate models derived from detailed data analyses and design calculations. A customization of some calculator blocks, through FORTRAN-based algorithms, has also been performed in order to monitor in the water stream some significant parameters, such as the electrical conductivity (EC). By exploiting the developed modules, the new treatments have been investigated through sensitivity analyses and the plant behaviour in the modified operating conditions has been assessed. Process analyses have been performed in order to understand the processes and to identify potential PI solutions, as well as to achieve improvements in the resource efficiency. These analyses were fundamental in order to plan further data collection by analysing piping and instrumentation diagrams (P and IDs) and equipment data sheets, as they allow scheduling ad hoc samplings or laboratory tests for missing or incomplete data. Models have been developed and tuned according to the collected data and validated.

The PM and S approach was suitable for studies in new designs as well as retrofits, such as fixed topology studies (no cost solutions), reuse studies involving re-piping opportunities (low cost solutions) or regeneration and reuse studies involving distributed treatments (medium cost solutions).

\section{Results and Discussion}

\subsection{Results of the First Case Study}

Before the trials the removal of colloids through UF was carried out, as the RO application for desalination is possible only if SDI $<3$ while, for raw water, SDI $>6$. With an average flow rate of feed water of $1.59 \mathrm{~m}^{3} / \mathrm{h}$, the recovery rate was $89.5 \%$, and after the UF $1<\mathrm{SDI}<2$. For this reason, UF appears necessary according to the required RO SDI. The RO trials consisted in two periods of two weeks. In the first trial, the concentrate was partially recirculated, with a salt rejection near $96 \%$. In the second period, without concentrate recirculation, the rejections and the recovery were $94.5 \%$ and $75 \%$, respectively.

The comparison between trials carried out with or without recirculation are depicted in Table 3 and the test results that have been obtained in the second period are presented in Figure 2. 


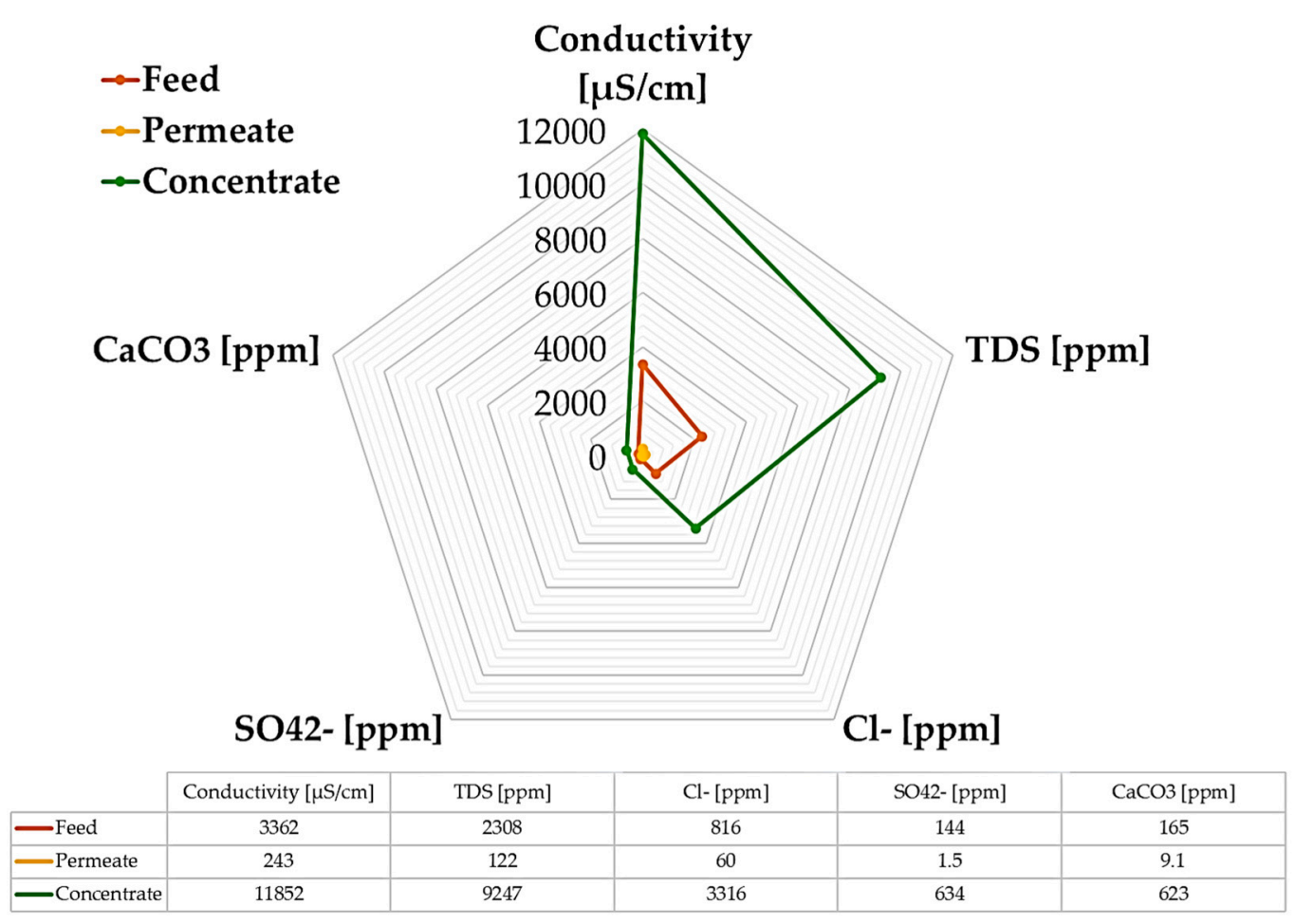

Figure 2. Test results in the case of no-retentate recirculation trials.

Table 3. Comparison between removal efficiency of the first and the second period trials.

\begin{tabular}{ccc}
\hline Removal Efficiency (\%) & $\begin{array}{c}\text { With Concentrate Recirculation } \\
\text { (First Period) }\end{array}$ & $\begin{array}{c}\text { Without Retentate Recirculation } \\
\text { (Second Period) }\end{array}$ \\
\hline Calcium & $99-100$ & $99.5-99.8$ \\
Alkalinity & $95-96.5$ & $93-95.5$ \\
Total Dissolved Solids-TDS & $94.5-97.9$ & $93-96.2$ \\
(Residue at $\left.105^{\circ} \mathrm{C}\right)$ & & \\
\hline
\end{tabular}

The salt removal process was very effective, as shown by the decrease of the EC value, the chlorides and fluorides, the alkalinity, the total dissolved solids (TDS) and calcium. To sum up, the permeate can be reused and the concentrate discharged into the sea. In general, in the steel sector, limits for discharging are specific for the production process. Although the contaminants in the concentrate can be a barrier, this is linked not only to the water body, where they are discharged, but also to the environmental regulations. Concerning the quality of the permeate, at the considered integrated steelworks, as it is of high quality, it is suitable for further application. As far as the concentrate is concerned, it is suitable to be discharged because, according to the Italian legislation [32], the limits for discharging chlorides and sulphates into the sea do not apply; for this reason, there are no costs related to further treatments of the concentrate.

As far as the industrial implementation of the process is concerned, the retentate recirculation is avoided. In effect, once the recovery factor, which depends on the salts concentrations affecting membranes scaling, is fixed, the concentrate recirculation implies costs that are not compensated by the higher removal efficiency achieved in this case due to the higher feeding flow rate and the larger facilities and pumping equipment that are required.

Results show that the permeate recovery obtained through $\mathrm{RO}$ is the $75 \%$ of the treated water, the recovery rate of UF is $89.5 \%$ and the EC of permeate from $180 \mu \mathrm{S} / \mathrm{cm}$ to $330 \mu \mathrm{S} / \mathrm{cm}$. These results allow reusing recovered water in different applications, by thus reducing water consumption in the cooling circuits due to the blowdown decrease. 


\subsection{Results of the Second Case Study}

In a first step, data related to water quality (e.g., ions content, calcium hardness, total hardness, $\mathrm{pH}$ value, electrical conductivity) have been taken into account, as well as the types of chemical compounds (e.g., salts and oxides). Additionally, in the present case, both Aspen Plus ${ }^{\circledR}$ commercial software and Water-Int software have been used. Data of salts, chemical species, and specific concentrations in water streams have been used as simulations inputs. The Water-Int software has been used for a simplified and preliminary assessment of water reuse, while the Aspen Plus ${ }^{\circledR}$ software has been exploited for a more detailed simulation, taking into account all the chemical and physical processes of the selected plant as well as different operating conditions. P and IDs, data about standard operating conditions of the unit operations involved in each analysed area and literature information have been considered, due to the lack of real data.

The flowsheet of the Aspen Plus ${ }^{\circledR}$ based model reproduces the plant areas considered as blowdown water receptor and user. Such a model includes operation/treatment units, which are often developed as a combination of different sub-units in order to consider different process aspects and obtain outputs close to real data. Only after the process validation of the whole model of the considered plant area can the modifications to be investigated be implemented and evaluated firstly without additional treatment units, and afterwards with the addition of new units.

\subsubsection{Reuse of Pipe Coating Blowdown in a Pipe Plant}

A model of one pipe mill washing water network in the considered steelworks (Figure 3) has been developed through Aspen Plus ${ }^{\circledR}$ V. 8.4 software (described in [36]) and validated by data from an internal industrial database or from ad hoc sampling in standard operating conditions.

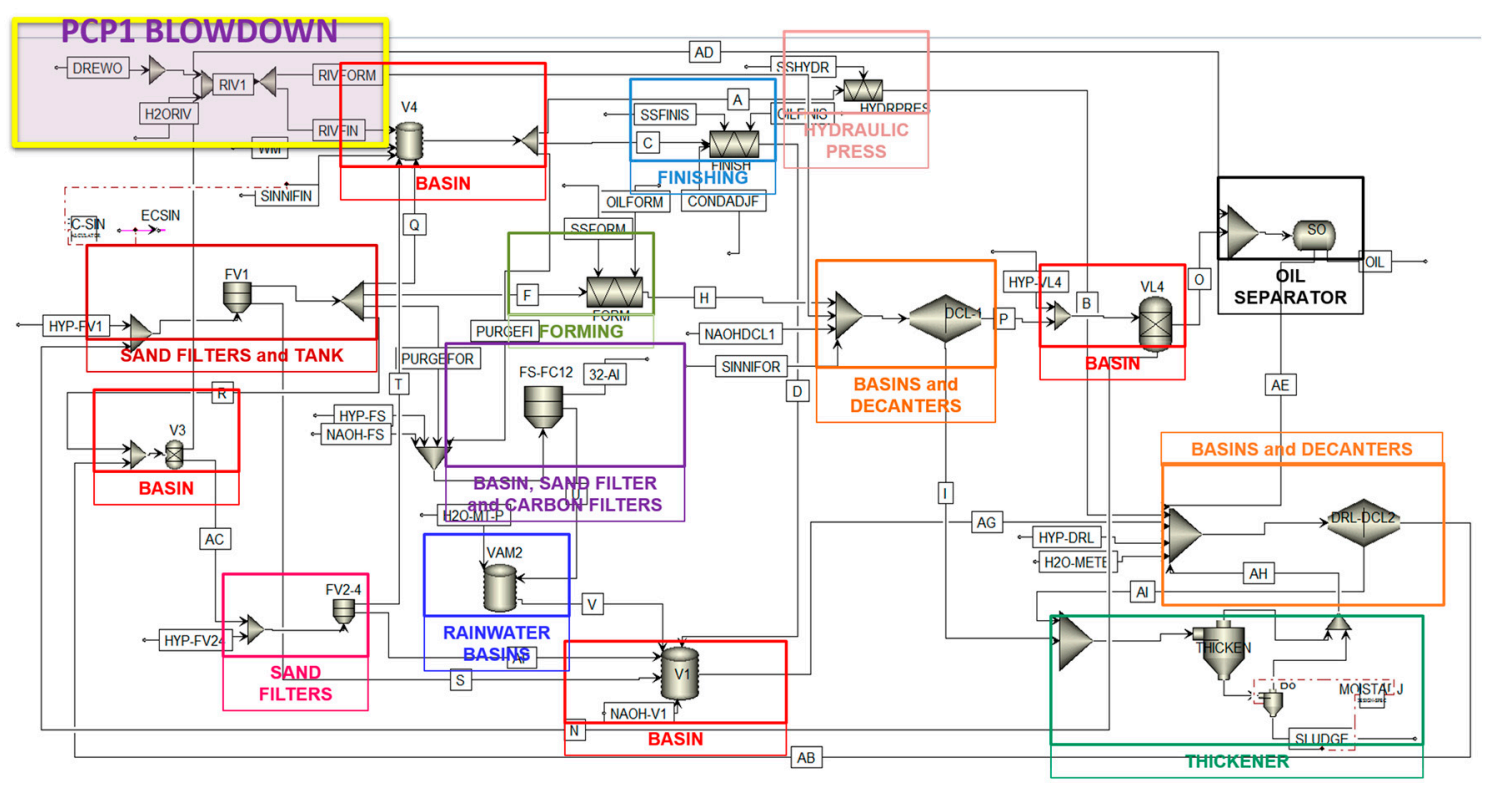

Figure 3. Aspen Plus ${ }^{\circledR}$ based flowsheet of pipe plant washing water network.

The water network includes washing systems of pipe forming (FORMING in Figure 3), pipe finishing (FINISHING in Figure 3), and a hydraulic press to test the pipe. Wastewater of the PP1 area, mainly containing oil, suspended solids, and some salts, is treated before recirculation and/or discharge, in accordance with discharge contaminant limits. Some chemicals, such as $\mathrm{NaOH}$ and $\mathrm{NaClO}$, are usually added in order to improve the water treatment efficiency and to control $\mathrm{pH}$. The stream to reuse is the blowdown coming from the pipe coating plant (PCP1 BLOWDOWN in Figure 3), with similar quality of the currently used make up water, drawn from the Sinni River. 
The modelling of the different water inputs (Sinni River water and PCP1 blowdown) has been carried out by following the approach described in [37].

Due to the complexity of real plant, the developed model has been simplified through some assumptions: for instance, similar unit operations were grouped as a single block, the washing processes were considered as producers of oil and suspended solids (SS). In order to take into account EC constraints in the water stream, some adjustments, such as the addition of a stream to consider salt contamination (represented by the EC value) in the finishing washing system are needed, since the real source of this salt is not completely known, but it must be considered. In addition, $\mathrm{NaClO}$ and $\mathrm{NaOH}$ concentrations are set at a $\mathrm{pH}$ value of $8.5-9.5$ in the whole water network.

In the simulation process, the monitored parameters, such as EC, SS, $\mathrm{pH}$, temperature, and oil concentration, are observed also using ad hoc-developed algorithms [38].

Results show that the partial replacement of the freshwater intake of the PP1 with the untreated PCP1 blowdown do not affect the quality of intermediate water stream; only negligible changes are observed for the inlet streams to the washing systems of forming (f stream) and of finishing (c stream) or to the hydraulic press (a stream), as depicted in Table 4.

Table 4. Comparison between inlet streams to the washing systems and to the hydraulic press, before and after PCP1 blowdown reuse.

\begin{tabular}{ccccccc}
\hline Stream & a & a_PCP1 $^{\mathbf{1}}$ & c & c_PCP1 $^{\mathbf{1}}$ & f & f_PCP $^{\mathbf{1}}$ \\
\hline pH & 8.2 & 8.4 & 8.2 & 8.4 & 8.2 & 8.3 \\
EC & 1774 & 1781 & 1774 & 1781 & 388 & 394 \\
$(\mu \mathrm{S} / \mathrm{cm})$ & & 148.4 & 93.3 & 148.3 & 33.5 & 32.9 \\
SS $(\mathrm{ppm})$ & 93.3 & 0.7 & 0.8 & 0.7 & 21.4 & 21.4 \\
Oil (ppm) & 0.8 & Note: ${ }^{1}$ PCP1 indicates the reuse of PCP1 blowdown.
\end{tabular}

This solution allows a reduction of the freshwater make-up by $20 \%$ : The total mass flow rate of make-up water decreases from $6080 \mathrm{~kg} / \mathrm{h}$ to $4830 \mathrm{~kg} / \mathrm{h}$. As far as the further effects are concerned, an increase of concentration of SS from $22.6 \mathrm{mg} / \mathrm{kg}$ to $24.8 \mathrm{mg} / \mathrm{kg}(+10 \%)$ in PP1 blowdown and an increase of sludge production from $11.2 \mathrm{~kg} / \mathrm{h}$ to $12.1 \mathrm{~kg} / \mathrm{h}(+8 \%)$ have been observed. As the quality of the PCP1 wastewater is good enough, although not at the level of the Sinni River fresh water, the current treatment unit operations are able to keep within reasonable limits the introduction of new contaminants (e.g., suspended solids, salts, etc.). However, if the reused water presents significant differences in the salinity content (i.e., EC), a further treatment could be necessary (e.g., RO) and further assessments should be done after treatment implementation in the model.

Simulation results proved the effectiveness of the considered solution showing that partial fresh PP1 water replacement with PCP1 blow down can be successfully applied on-line.

\subsubsection{Reuse of Coke-Making Area Wastewater}

The Water-Int software which included some developed Excel-based treatment mathematical models, has been used to assess the possible reuse of discharge water from the final treatment (ammonia stripping) of the water network in the coke production area. The Water-Int software generates a water network design aiming at minimizing the operating costs by starting from unconnected blocks, as shown in Figure 4. This task has been accomplished by collecting specific information: contaminants concentrations in water sources, water user's constraints, and treatment operating costs.

The Water-Int simulation presents three types of blocks: Water sources, which are the fresh water and the ammonia stripping water, with their features; Water treatments, that are, in this case, UF and RO containing their MS-Excel mathematical model; Water users, with its constraints. 


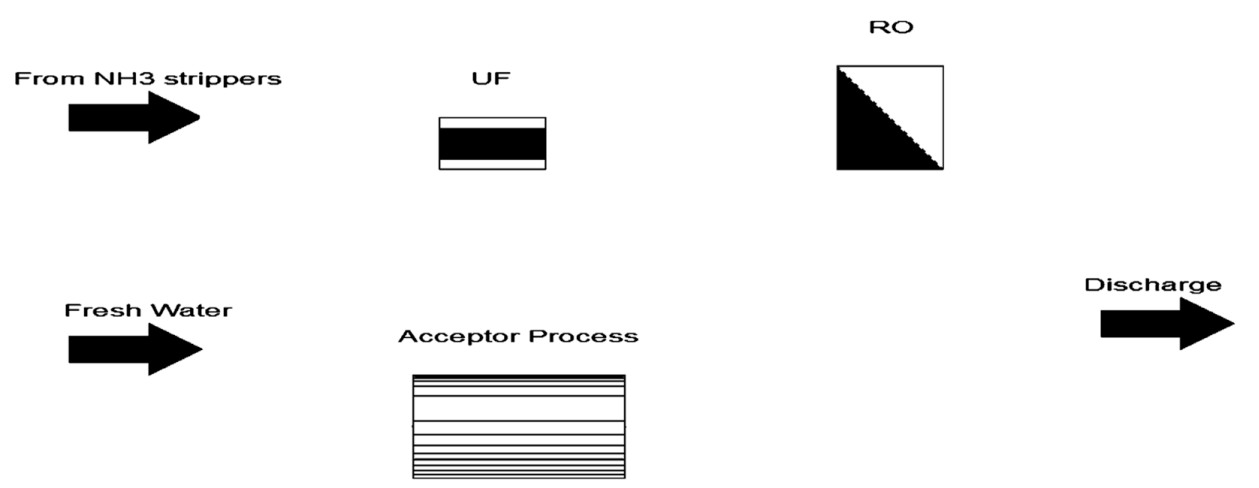

Figure 4. Water-Int model before simulation: unconnected blocks.

The simulation designs a potential water network that, according to the process constraints, minimizes the operating costs. Results show that recovery and reuse of coke-making area wastewater after desalination treatment to replace fresh water is more suitable than discharge, although a partial discharge is needed in order to prevent contaminants concentration. In addition, very high quality water can be obtained by applying UF and RO in series. Due to this reason, it is sufficient to treat only a part of the UF output with RO and then mix the untreated UF output with RO permeate to fulfill the water user constraints. The obtained configuration is shown in Figure 5.

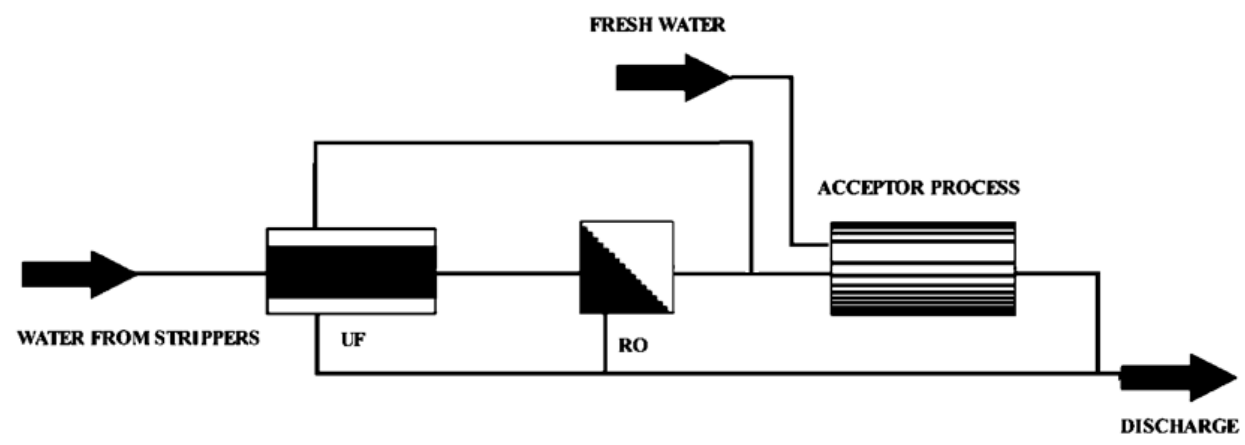

Figure 5. Obtained configuration after the Water-Int simulation.

Additionally, in this case, as in the first case study, the retentate is suitable to be discharged without additional treatments and related costs because it is in line with Italian regulations [32].

\subsection{Economic Viability}

The economic analysis has been carried out in terms of SPBP and DPBP in order to evaluate if the joint application of UF and RO was feasible and viable from an economic and financial point of view. In the case studies where they have been exploited, a water stream of high quality was always obtained. In effect, both applications allow a nearly complete removal of the contaminants and a recovery of about $70 \%$ of the inlet stream. The SPBP and DPBP analysis has been carried out by varying the prices of the recovered permeate streams and the concentrate streams. The permeate represented high-quality water suitable to replace part of the external freshwater intake and/or improve the availability for quality demanding water. On the other hand, the permeate quality must be evaluated, as it might be used for less demanding water in the various processes. The disposal of the retentate does not represent a cost, as the amount of contaminants allows, in any case, its discharge, according to Italian regulations [32]. The analysis is based on early assumptions, such as the knowledge of input and output streams and specific consumptions necessary for the estimation of the annual operating costs. The considered aspects are the continuous availability of water to be desalted, the size of the investment, the operating costs, and the savings of UF and RO. 
The capital expenditure (CAPEX) has been estimated around 1.2 M€ for a plant treating about $100 \mathrm{~m}^{3} / \mathrm{h}$ of wastewater (about $830,000 \mathrm{~m}^{3} / \mathrm{y}$ ) with a permeate yield around $60 \%$, from a precautionary point of view. The main operating costs are related to energy, maintenance and chemicals/membrane, as well as the workers and the depreciation cost. The considered depreciation time is five years with a depreciation rate of about $5 \%$. From the economic analysis, the operating cost is about $0.22 € / \mathrm{m}^{3}$ without considering the depreciation. The main savings are referred not only to the missing disposal cost of the wastewater, but also to the prices of the recovered permeate and retentate streams water. The retentate price has been considered depending on the lower quality with respect to the permeate and it has been reduced about $50 \%$. The plant operative life, without substantial revamping, is estimated to be 20 years. As shown in the Figure $6 a, b$, the results of the economic viability analysis show SPBP and DPBP values lying between 2.5 and 15 years for the RO implementation. Both results of SPBP and DPBP decrease with the increase of the permeate and retentate prices, but SPBP decreases faster with a rapid recovery rate for the investment. Actually, from a more accurate analysis, the DPBP reveals that the investment is viable and feasible, with a DPBP of less than 10 years, starting from the range of both prices: $0.45 € / \mathrm{m}^{3}$ for the retentate stream, and $0.8 € / \mathrm{m}^{3}$ for the permeate stream.

Therefore, the higher the prices of permeate and concentrate, the lower the times to recover the amount of investment. A variation on the boundary conditions, such as the availability and the cost of freshwater, as well as the cost of chemicals/membrane and energy required, can change the results of the analysis.

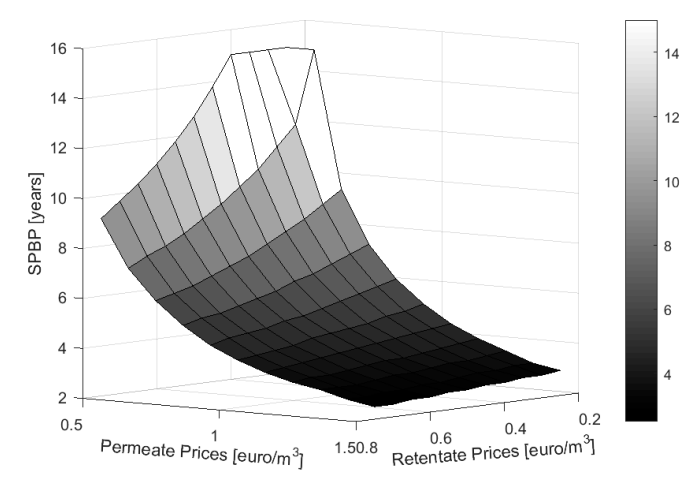

(a)

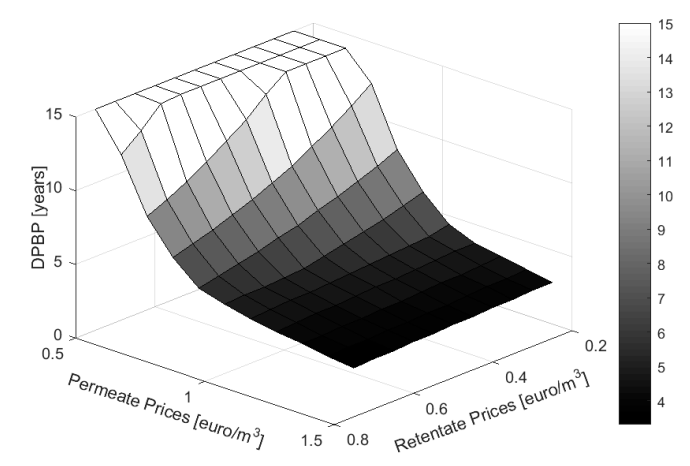

(b)

Figure 6. (a) SPBP results by varying the prices of the retentate and permeate streams; (b) DPBP results by varying the prices of the retentate and permeate flows.

\section{Conclusions}

The paper presents two cases studies related to the application of desalination technologies (if required) for improving wastewater reuse in the steel sector and to the exploitation of modelling and simulation in order to evaluate some PI opportunities. The results of the first case study show the technical and economic viability of the integration of RO in HSM, for treating make-up water before its introduction into the circuit. In addition, the UF pre-treatment is applied to remove suspended solids, colloidal substances, and microorganisms from the brackish water. Results show that RO effectively removes most salts, decreasing other parameters (e.g., electrical conductivity); the permeate is reused in the circuit and the concentrate is discharged into the sea.

Moreover, modelling and simulation approaches provide other relevant results in the evaluation of other possibilities of water reuse with or without treatments. Such approaches allow evaluating the viability of PI solutions, as well as the possibility of significant water recovery, taking into consideration the main parameters and treatments. The achieved results show how the simulation studies are important in the plant analyses, modification of process conditions, and improvement of technologies. In particular, it has been shown that sometimes blowdown waters coming from some plant areas can 
be exploited without treatment in other plant areas with admissible changes in the water inside the network. On the other hand, in other cases desalination treatment are required and allow obtaining significant advantages in terms of environmental and economic sustainability.

Indeed, after an economic assessment, the UF and RO process implementations appear feasible and can lead to advantages even if their viability depends on the overall situation of the considered plant, on the price of energy, and on the cost and availability of the freshwater.

The success of desalination methods has led many industries to their application in order to reduce the environmental impact and to save money. The application of $\mathrm{RO}$ for wastewater treatment, in order to improve water reuse and valuable component recovery, represents a promising achievement in wastewater recovery in the steel sector. Furthermore, compared to previous published works, this paper presents some innovative aspects. Along with positive results on salt elimination and water reuse and, consequently, on the environmental impact, further improvements can be achieved regarding the pipe service life [39] and product quality, as well as on the economic and technical features. In addition, the achieved technical solutions will be integrated into circuits of specific plants in the considered integrated steelworks. The relevant obtained results represent a further achievement for the implementation and transferability to other plants.

The good results obtained in the two analysed case studies pave the way to the next step required before the implementation of the assessed solutions, consisting in the real scale design of the treatment units and/or of the required piping. Furthermore, auxiliary units, such as pumps, need to be selected and operating conditions need to be optimized in view of the full-scale implementation of the proposed solutions.

Acknowledgments: The work described in the present paper has been developed within the projects entitled "Selective salt elimination and valorisation for sustainable water and facility management in the steel industry" (contract No. RFSR-CT-2010-00035) and "REFFIPLANT Efficient Use of Resources in Steel Plants through Process Integration" (contract No. RFSR-CT-2012-00039) that have received funding from the Research Fund for Coal and Steel of the European Union. The sole responsibility of the issues treated in the present paper lies with the authors; the Commission is not responsible for any use that may be made of the information contained therein.

Author Contributions: V.C. supervised the whole research activity, V.C. and I.M. conceived the modelling and simulation activities; I.M. developed the Aspen simulations, T.A.B. analyzed the data, B.F. developed the economic analysis, F.R. designed and performed the industrial experiments; L.R. analyzed the industrial applicability of the proposed solutions; all the authors jointly analyzed the results of both simulations and experiments,; V.C., I.M., T.A.B. and B.F. wrote the paper.

Conflicts of Interest: The authors declare no conflict of interest.

\section{References}

1. Klemeš, J.J.; Varbanov, P.S.; Kravanja, Z. Recent developments in process integration. Chem. Eng. Res. Des. 2013, 91, 2037-2053. [CrossRef]

2. Water, N. Wastewater recycling: Swedish steel plant goes green. Filtr. Sep. 2009, 46, 42-43.

3. World Steel Association. Available online: https://www.worldsteel.org/en/dam/jcr:f7594c5f-9250-4eb3aa10-48cba3e3b213/Water+Management+Position+Paper+2015.pdf (accessed on 15 September 2017).

4. World Steel Association. Available online: https://www.worldsteel.org/publications/bookshop/product-details. $\sim$ Water-management-in-the-steel-industry PRODUCT Water .html (accessed on 15 September 2017).

5. Stillwell, A.S.; Webber, M.E. Predicting the specific energy consumption of reverse osmosis desalination. Water 2016, 8. [CrossRef]

6. Suvio, P.; van Hoorn, A.; Szabo, M. Water usage in steel making: Findings from a worldsteel water management project. Stahl und Eisen 2010, 130, S39-SP50.

7. Van Caneghem, J.; Block, C.; Cramm, P.; Mortier, R.; Vandecasteele, C. Improving eco-efficiency in the steel industry: The arcelormittal gent case. J. Clean. Prod. 2010, 18, 807-814. [CrossRef]

8. Galiana-Aleixandre, M.; Iborra-Clar, A.; Bes-Piá, B.; Mendoza-Roca, J.; Cuartas-Uribe, B.; Iborra-Clar, M. Nanofiltration for sulfate removal and water reuse of the pickling and tanning processes in a tannery. Desalination 2005, 179, 307-313. [CrossRef] 
9. Suksaroj, C.; Heran, M.; Allegre, C.; Persin, F. Treatment of textile plant effluent by nanofiltration and/or reverse osmosis for water reuse. Desalination 2005, 178, 333-341. [CrossRef]

10. Wisniewski, J.; Suder, S. Water recovery from etching effluents for the purpose of rinsing stainless steel. Desalination 1995, 101, 245-253. [CrossRef]

11. Clever, M.; Jordt, F.; Knauf, R.; Räbiger, N.; Rüdebusch, M.; Hilker-Scheibel, R. Process water production from river water by ultrafiltration and reverse osmosis. Desalination 2000, 131, 325-336. [CrossRef]

12. Lee, J.-W.; Kwon, T.-O.; Moon, I.-S. Performance of polyamide reverse osmosis membranes for steel wastewater reuse. Desalination 2006, 189, 309-322. [CrossRef]

13. Huang, X.-F.; Ling, J.; Xu, J.-C.; Feng, Y.; Li, G.-M. Advanced treatment of wastewater from an iron and steel enterprise by a constructed wetland/ultrafiltration/reverse osmosis process. Desalination 2011, 269, 41-49. [CrossRef]

14. Madwar, K.; Tarazi, H. Desalination techniques for industrial wastewater reuse. Desalination 2003, 152, 325-332. [CrossRef]

15. Alcamisi, E.; Matino, I.; Porzio, G.; Colla, V. Wastewater treatment in iron and steel industry: Process integration for water re-use. In Proceedings of the 1st International Process Integration Forum for the Steel Industry, Luleå, Sweden, 9-10 June 2014.

16. Gundersen, T. A Worldwide Catalogue on Process Integration; International Energy Agency (IEA): Paris, France, 1997.

17. Porzio, G.F.; Colla, V.; Matarese, N.; Nastasi, G.; Branca, T.A.; Amato, A.; Fornai, B.; Vannucci, M.; Bergamasco, M. Process integration in energy and carbon intensive industries: An example of exploitation of optimization techniques and decision support. Appl. Therm. Eng. 2014, 70, 1148-1155. [CrossRef]

18. Wang, Y.; Smith, R. Wastewater minimisation. Chem. Eng. Sci. 1994, 49, 981-1006. [CrossRef]

19. Porzio, G.; Alcamisi, E.; Matino, I.; Colla, V. An integrated approach for industrial water systems optimal design. In Proceedings of the 2014 NSTI Nanotechnology Conference and Expo, NSTI-Nanotech, Washington, DC, USA, 12-15 May 2014; pp. 529-532.

20. Mooney, E.; Semkov, K.; Adley, C.; Mooney, C. Addressing energy and environmental targets through combined process integration techniques. Chem. Eng. Trans. 2013, 35, 187-192.

21. Porzio, G.F.; Colla, V.; Fornai, B.; Vannucci, M.; Larsson, M.; Stripple, H. Process integration analysis and some economic-environmental implications for an innovative environmentally friendly recovery and pre-treatment of steel scrap. Appl. Energy 2016, 161, 656-672. [CrossRef]

22. Gao, C.; Wang, D.; Dong, H.; Cai, J.; Zhu, W.; Du, T. Optimization and evaluation of steel industry's water-use system. J. Clean. Prod. 2011, 19, 64-69. [CrossRef]

23. Simate, G.S. The treatment of brewery wastewater for reuse by integration of coagulation/flocculation and sedimentation with carbon nanotubes 'sandwiched' in a granular filter bed. J. Ind. Eng. Chem. 2015, 21, 1277-1285. [CrossRef]

24. Sueviriyapan, N.; Siemanond, K.; Quaglia, A.; Gani, R.; Suriyapraphadilok, U. The optimization-based design and synthesis of water network for water management in an industrial process: Refinery effluent treatment plant. Chem. Eng. 2014, 39, 133-138.

25. Mosqueira-Salazar, K.; Palacios-Bereche, R.; Chávez-Rodríguez, M.; Seabra, J.; Nebra, S. Reduction of water consumption in an integrated first-and second-generation ethanol plant. Energy Sustain. Dev. 2013, 17, 531-535. [CrossRef]

26. Chavez-Rodriguez, M.F.; Mosqueira-Salazar, K.J.; Ensinas, A.V.; Nebra, S.A. Water reuse and recycling according to stream qualities in sugar-ethanol plants. Energy Sustain. Dev. 2013, 17, 546-554. [CrossRef]

27. Hosseini, N.; Johnston, J.; Lindenschmidt, K.-E. Impacts of climate change on the water quality of a regulated prairie river. Water 2017, 9. [CrossRef]

28. Bassi, A.M.; Tan, Z.; Goss, S. An integrated assessment of investments towards global water sustainability. Water 2010, 2, 726-741. [CrossRef]

29. Kim, J. Process integration and conceptual design with process simulators. Chem. Eng. Trans. 2009, 18, 833-838.

30. Du, J.; Chen, J.; Li, J.; Meng, Q. Water allocation network synthesis involving reliability analysis. Chem. Eng. Trans. 2013, 35, 31-36.

31. Colla, V.; Branca, T.A.; Rosito, F.; Lucca, C.; Vivas, B.P.; Delmiro, V.M. Sustainable reverse osmosis application for wastewater treatment in the steel industry. J. Clean. Prod. 2016, 130, 103-115. [CrossRef]

32. Lgs, D. 152/06 e smi "norme in materia ambientale". Gazzetta Ufficiale, 14 April 2006. 
33. Levy, H.; Sarnat, M. Capital Investment and Financial Decisions; Pearson Education: Edimburgh, UK, 1994.

34. Bierman, H., Jr.; Smidt, S. The Capital Budgeting Decision: Economic Analysis of Investment Projects; Routledge: Abingdon, UK, 2012.

35. Yard, S. Developments of the payback method. Int. J. Prod. Econ. 2000, 67, 155-167. [CrossRef]

36. Matino, I.; Colla, V.; Alcamisi, E.; Porzio, G.F. Evaluation of water blowdown reuse in integrated steelworks through process simulation. In Proceedings of the 2nd European Steel Technology and Application Days, Dusseldorf, Germany, 15-19 June 2015.

37. Alcamisi, E.; Matino, I.; Vannocci, M.; Colla, V. Simplified ionic representation of industrial water streams. In Proceedings of the 2014 European Modelling Symposium (EMS), Pisa, Italy, 21-23 October 2014; pp. 286-290.

38. Matino, I.; Alcamisi, E.; Porzio, G.F.; Colla, V. Application of unconventional techniques for evaluation and monitoring of physico-chemical properties of water streams. Int. J. Simul. Syst. Sci. Technol. 2015, 16. [CrossRef]

39. De la Fuente, D.; Morcillo, M.; Ivashechkin, P.; Colla, V.; Branca, T.; De Sanctis, M.; Vivas, B.; Cabaas, M.; Rassow, A.; Lucca, C. Sustainable water and facility management in the steel industry: Influence of saline streams on pipeline corrosion. In Proceedings of the European Corrosion Congress EUROCORR 2014, Pisa, Italy, 8-12 September 2014.

(C) 2017 by the authors. Licensee MDPI, Basel, Switzerland. This article is an open access article distributed under the terms and conditions of the Creative Commons Attribution (CC BY) license (http://creativecommons.org/licenses/by/4.0/). 